Research Article

\title{
Determinants of Anemia among Pregnant Women at Public Hospitals in West Shewa, Central Ethiopia: A Case-Control Study
}

\author{
Berhanu Senbeta Deriba $\left(D^{1},{ }^{1}\right.$ Elias Teferi Bala, ${ }^{2}$ Gizachew Abdissa Bulto $\left(\mathbb{D},{ }^{3}\right.$ \\ Tinsae Abeya Geleta, ${ }^{1}$ Agumas Fentahun Ayalew, ${ }^{1}$ Addis Adera Gebru, ${ }^{1}$ \\ Habtamu Oljira Desta, ${ }^{2}$ Mengistu Benayew Shiferaew, ${ }^{4}$ and Lidya Zerihun Sahile ${ }^{4}$ \\ ${ }^{1}$ Salale University, Department of Public Health, Fiche, Ethiopia \\ ${ }^{2}$ Ambo University, Department of Public Health, Ambo, Ethiopia \\ ${ }^{3}$ Ambo University, Department of Midwifery, Ambo, Ethiopia \\ ${ }^{4}$ Salale University, Department of Nursing, Fiche, Ethiopia \\ Correspondence should be addressed to Berhanu Senbeta Deriba; berhanusenbeta55@gmail.com
}

Received 8 May 2020; Revised 21 October 2020; Accepted 18 November 2020; Published 28 November 2020

Academic Editor: Duran Canatan

Copyright (C) 2020 Berhanu Senbeta Deriba et al. This is an open access article distributed under the Creative Commons Attribution License, which permits unrestricted use, distribution, and reproduction in any medium, provided the original work is properly cited.

\begin{abstract}
Introduction. Anemia is highly dominant among pregnant women due to the need for iron for women themselves and their fetuses. Nearly half a billion globally and around one-third in Ethiopia of pregnant women were affected by anemia which has both health and economic impact. Therefore, this study aimed to identify the determinants of anemia among pregnant women attending antenatal care at public hospitals in the West Shewa zone, Oromia regional state, Central Ethiopia, 2019. Methods. An unmatched case-control study was conducted at public hospitals in the West Shewa zone, Ethiopia, from February to April 2019. A consecutive sampling was used to select study participants. Data were collected by a structured questionnaire, and the collected data were entered into Epi Info version 7 and SPSS version 23 for analyses. Descriptive statistics such as tables, graphs, and proportions were used to present the data. Binary and multiple logistic regression analyses were computed to identify the determinants of anemia. Adjusted odds ratio (AOR) with $95 \%$ confidence interval (CI) and $p$ value $<0.05$ were used to determine the presence of an association. Result. A total of 426 women (142 cases and 284 controls) participated in this study with a $95.3 \%$ response rate. Family size $>5(\mathrm{AOR}=2.95,95 \% \mathrm{CI}: 1.34-6.50)$, peptic ulcer diseases (PUD) $(\mathrm{AOR}=2.85,95 \% \mathrm{CI}: 1.14-7.13)$, having the previous history of abortion $(\mathrm{AOR}=2.84,95 \% \mathrm{CI}: 1.08-7.47)$, birth interval $<2$ years $(\mathrm{AOR}=2.61,95 \% \mathrm{CI}: 1.20-5.70)$, antepartum hemorrhage $(\mathrm{APH})(\mathrm{AOR}=6.05,95 \% \mathrm{CI}: 1.95-18.81)$, and not using latrine (AOR $=3.45,95 \% \mathrm{CI}: 1.30-9.24)$ were the identified determinants of anemia. Conclusions. Family size, PUD, abortion, birth interval, APH, and unable to use latrine were the determinants of anemia among pregnant women. Therefore, the intervention on anemia prevention should consider the promotion of family planning methods and counseling on latrine utilization.
\end{abstract}

\section{Introduction}

World Health Organization (WHO) explained anemia in pregnancy as a hemoglobin level below $11 \mathrm{gm} / \mathrm{dl}$ [1]. A type of anemia that most commonly affects women of childbearing age especially pregnant mothers is iron deficiency anemia [2]. Anemia is highly dominant among pregnant women due to the need for iron for women themselves and for their fetuses [1]. Globally, nearly half a billion of reproductive-age women are affected by anemia where about $29 \%$ of nonpregnant women and $38 \%$ of pregnant women aged 15-49 years [3]. In Ethiopia, around 32\% of pregnant women are affected by anemia [4]. Anemia in pregnancy causes reduced cognitive and motor development outcomes in children due to inherited hemoglobin diseases [5]. It also contributed to $8.8 \%$ of disabilities globally [6]. Anemia causes $20 \%$ of maternal death globally [7,8]. Anemia in pregnancy may result in premature birth, low birth weight, 
and maternal, perinatal, and neonatal mortality [9]. The reason why anemia remains a public health problem is mainly due to inadequate nutrient intake, excessive menstrual bleeding, acute or chronic blood loss (gastrointestinal bleeding), infections (malaria and HIV), chronic diseases, parasites infestation, hemolytic anemia (drugs), and frequent pregnancies [10-12]. Different factors are known to cause anemia in pregnancy in sub-Saharan Africa. These include diet deficiency and infections such as malaria, hookworms, and increasingly spread human immunodeficiency virus. Most of these circumstances can be prevented by creating awareness and affordable interventions [13]. WHO intended to decrease anemia among reproductive-age women including pregnant women by $50 \%$ up to 2025 [14]. The Ethiopian Ministry of Health tried to mitigate the problem of anemia and its impact through the implementation of essential nutrition action [15]. Despite the high magnitude of anemia among pregnant women which results in high morbidity and mortalities among pregnant women and high economic losses in Ethiopia, the majority of the previously conducted studies in different parts of the word including Ethiopia were done using a cross-sectional study which is weak in displaying real association between anemia and its risk factors [10, 16-24]. The availability of local information on the determinants of anemia is important to solve the problem of anemia at its grass roots. Most of the previous cross-sectional studies conducted in Ethiopia recommended analytic study like case-control studies to be conducted [10, 16, 22, 25, 26]. Moreover, personal hygiene and sanitation-related predictors of anemia like source of water for drinking, hand washing at important times, and utilization of latrine were not studied with regard to anemia in pregnancy in Ethiopia. Although open-field defecation is very common in Ethiopia, its relationship with anemia was not studied. Therefore, this study aimed to identify determinants of anemia among pregnant women attending antenatal care at public hospitals of the West Shewa zone, Oromia regional state, Central Ethiopia.

\section{Method and Materials}

2.1. Study Design, Period, and Setting. We have conducted an institution-based unmatched case-control study from February to April 2019 in all public hospitals available in the West Shewa zone. The capital city of the zone is Ambo which is 114 kilometers far from the capital city of the country, Addis Ababa. The West Shewa zone has a total population of 2,650,781 from which 91,982 were pregnant women according to West Shewa zonal health office report of January 2019 [27]. The zone has 90 health centers, three general hospitals, four district hospitals, and one referral hospital. The study was conducted in eight public hospitals that give ANC, delivery, and postnatal care services.

2.2. Source Population and Study Population. All pregnant women (15-49 years old) that came for the first antenatal care follow-up at public hospitals in the West Shewa zone during the data collection period were the source populations whereas all pregnant women (15-49 years old) who came for the first antenatal care follow-up at public hospitals in the West Shewa zone during the data collection period and included in the study were the study populations. All pregnant women attending the first visit of their antenatal care at public hospitals in the West Shewa zone and voluntary to participate were included in study. Pregnant women on therapy of severe anemia and unable to respond were excluded from the study. Those with hemoglobin level $<11 \mathrm{~g} / \mathrm{dl}$ were considered as cases whereas those with hemoglobin level greater than or equal to $11 \mathrm{~g} / \mathrm{dl}$ were considered as controls according to the WHO definition for the diagnosis of anemia in pregnancy [1]. The reason why the first visit of ANC was selected was that because those who were on repeated follow-ups were likely to take iron and folic acid supplementations during their previous visit the risk of being anemic is reduced.

2.3. Sample Size Determination. The sample size was calculated by using two population proportion formula, and it was calculated through Epi Info 7 statistical software package with the assumption of confidence level 95\% $(\mathrm{Z} \alpha / 2=1.96)$, power $80 \%(Z \beta=0.84)$, and case-control ratio $1: 2$, where $p 1$ is the proportion of cases, exposed and $p^{2}$ is the proportion of controls exposed. The variable first trimester of pregnancy was considered as a determinant of anemia as identified by a study conducted in Dessie town, Ethiopia, where $p 1=42.1 \%$, $p 2=18.8 \%$, and AOR $=2.07$ [26]. Therefore, the final sample size was 149 cases and 298 controls with a total of 447 pregnant women after adding a $15 \%$ nonresponse rate.

2.4. Sampling Technique. The study was conducted in all (eight) hospitals present in the West Shewa zone. The numbers of study participants were allocated proportionally to the average number of pregnant women who could attend the first visit of the ANC during the data collection period, which was estimated from average numbers of previous months' (previous quarter) antenatal care users which was taken from ANC registration books of each hospital. Therefore, the sample of each hospital was calculated by multiplying the average number of pregnant women attending the first antenatal care in each hospital per month with a total sample size $(n=447)$, dividing by the total number of pregnant women attending antenatal care unit per month at all hospitals (2187) (Figure 1). Consecutive sampling was used to select study participants (after collecting data from one case, data were also collected from two consecutive controls at each public hospital).

2.5. Operational Definitions. Anemia in pregnancy was defined by hemoglobin level adjusted at sea level altitude based on WHO criteria. So, anemia in pregnancy was defined as when the hemoglobin level is $<11 \mathrm{gm} / \mathrm{dl}$ [1]. According to WHO definition for the diagnosis of anemia in pregnancy, pregnant women with hemoglobin level $<11 \mathrm{~g} / \mathrm{dl}$ were considered as cases (anemic), whereas those with 


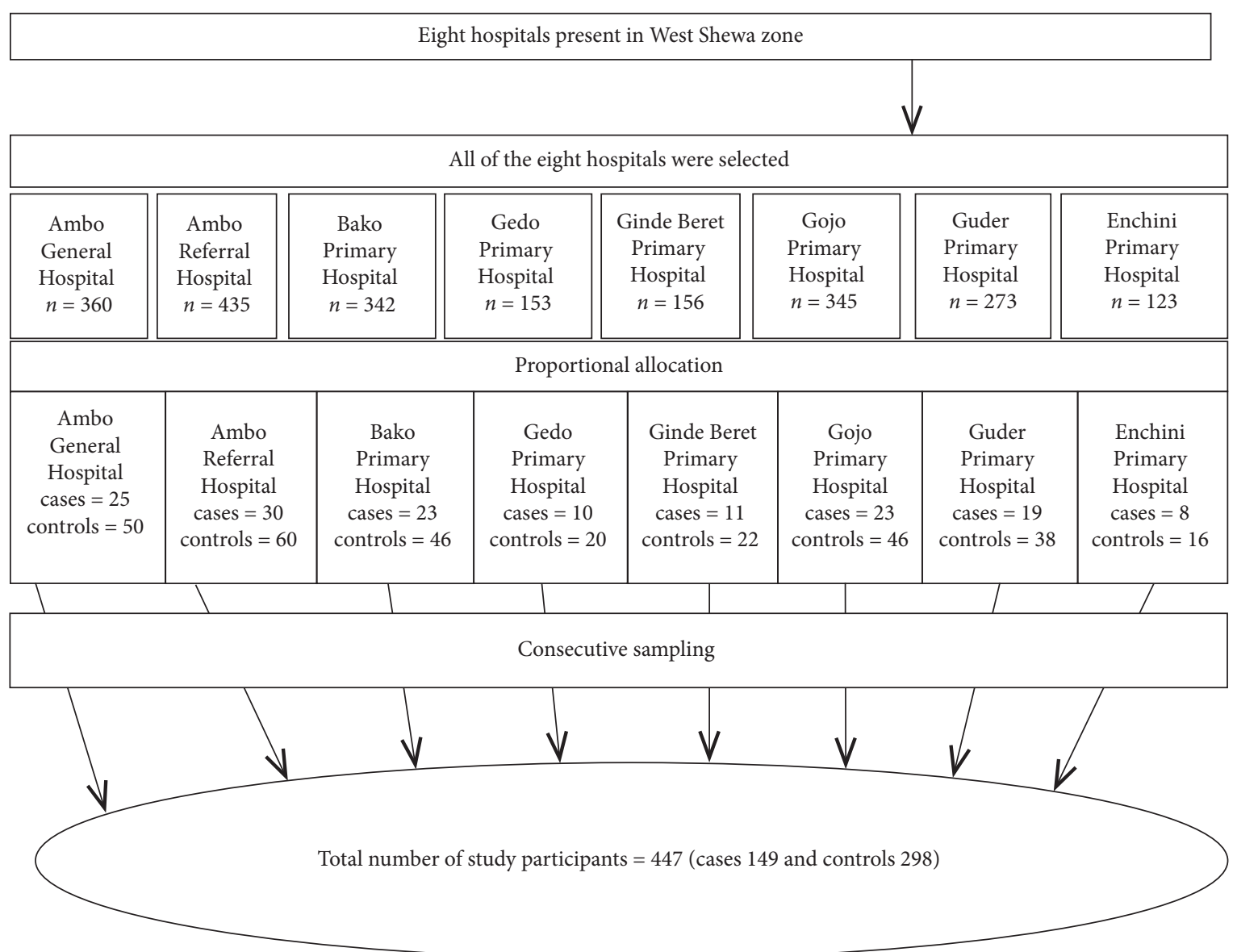

FIGURE 1: Schematic representation of pregnant women attending ANC in public hospitals of West Shewa zone from February to April 2019.

hemoglobin level $\geq 11 \mathrm{~g} / \mathrm{dl}$ were considered as controls (nonanemic) [1].

Gastritis/PUD is characterized by epigastric pain, epigastric tenderness, hematemesis, and positive for $H$. pylori test and ulcer identified by the endoscope. A respondent who had at least one of the health problems mentioned above was considered to have gastritis or PUD [28].

2.6. Data Collection Tool and Procedure. Data were collected through face-to-face interviews by standardized structured questionnaires; the majority of which were adapted and modified from the previous studies [29]. Eight BSC midwives and two senior experienced midwife professionals were selected for data collection and supervision, respectively. Information related to sociodemographic characteristics and pregnancy-related (obstetrics and gynecologic variables) factors of respondents was collected through faceto-face interview by using a pretested structured questionnaire which was done after laboratory test results were obtained because cases and controls cannot be identified before hemoglobin test results. Necessary history and physical examination with laboratory investigations were taken and done for all respondents who permitted their consent to identify diseases and pregnancy-related characteristics of mothers.
2.7. Specimen Collection and Processing. Eight trained laboratory technologists conducted specimen collection and processing at eight hospitals. Four senior experienced and trained laboratory technologists supervised every step of specimen collection, processing, and analysis. The blood for hemoglobin concentration, HIV (was done after counseling), and malaria diagnosis was done based on the standard operating procedures (SOPs). A venous blood sample $10 \mathrm{ml}$ was taken from study participants, by using a HemoCue $\mathrm{Hb}$ 301 analyzer (manufactured by HemoCue $\mathrm{AB}$ ) a precalibrated instrument was designed for measurement of hemoglobin concentration and labeled with identification number. The venous blood was drawn through micro cuvettes and inserted into HemoCue $\mathrm{Hb}$ analyzer and the result was recorded. To examine blood for malaria, HIV serostatus, and syphilis tests, the blood of pregnant women that was collected for hemoglobin test was used.

Stool specimen container was given to every pregnant woman with toilet tissue paper and clean applicator stick after questionnaire administration to bring fresh stool specimen. Information was to the pregnant woman on how to collect enough amount and contamination-free specimen. Woman was requested to bring the stool sample quickly to process and examine within two hours. The laboratory technologists checked whether sufficient amount of stool specimen was collected or not, when receiving the specimen. 
A portion of stool was processed with direct microscopic technique to detect intestinal parasites immediately. The sample was examined microscopically first with $10 \mathrm{x}$ and then with 40x objective for the detection of helminthes, eggs, and cysts of protozoan parasites. Stool examination was done by using formal ether concentration technique, which is considered the most sensitive for most intestinal helminthes. The same method was carried out across all (eight) hospitals.

2.8. Data Quality Control and Management. Two days of training were given for data collectors and supervisors on the objective of the study, contents of the questionnaire, confidentiality, the right of respondents, and how to collect data. The questionnaire was pretested on 5\% (7 cases and 14 controls) of the sample to assess the reliability of the data collection instruments at Tulu Bolo Hospital. After the pretest, the investigators, data collectors, and supervisors discussed the questionnaire so that the tool was modified for any inconsistencies and ambiguity before actual data collection. The laboratory procedure quality was guaranteed by giving training for laboratory technologists through a standard operating procedure (SOP) and regular monitoring of reagents, expiry date, and proper storage. The collected data were checked by supervisors and data collectors for consistency and completeness every day at the end of each data collection day and necessary corrective measures were taken from the area where difficulty was identified.

2.9. Data Processing and Analysis. After data collection, data were checked for completeness and coded, cleaned, and entered into Epi Info version 7 and transported to SPSS version 23 for data cleaning and analysis. After cleaning data for inconsistencies and missing values, descriptive statistics such as tables, graphs, and proportions were used to present data. Bivariate and multivariate logistic regression analyses were carried out to determine the presence of an association between dependent and independent variables. Variables with a $p$ value less than 0.25 at $95 \% \mathrm{CI}$ in the bivariate logistic regression were entered into a multivariate logistic regression [30]. Multiple logistic regressions were carried out to identify the determinants of anemia among pregnant women. The model goodness-of-fit test was checked by Hosmer-Lemeshow goodness of fit, and the $p$ value of the model fitness test was 0.87 . Multicollinearity and confounding effect were checked by using standard error which was not inflated, and no collinearity exists between the independent variables. Then all candidate variables were entered into a multivariate model since no collinearity was found between them. Finally, AOR with $95 \% \mathrm{CI}$ and $p$ value $<0.05$ were considered as statistically significant.

2.10. Ethical Consideration. The study protocol and methodology were approved by Ambo University College of Medicine and health sciences ethical review committee with reference number MHSC-PG: 003/2019. The permission to conduct study was obtained from the West Shewa zone health office and from all hospitals. Written consent was obtained from study participants after explaining the objective and purpose of the study to all study participants who were above 18 years old, and written assent was obtained from their parents or guardians where the study participants were pregnant women under 18 years of age. Those mothers who were found to have anemia, PUD, STI, hypertension, diabetes, malnutrition, and parasites were treated and linked to appropriate units in the hospitals for follow-up immediately after diagnosis.

\section{Result}

3.1. Sociodemography-Related Characteristics of Study Participants. A total of 426 pregnant women (142 cases and 284 controls) participated in this study making a response rate of $95.3 \%$. The age of respondents ranged from 17 to 39 years with the mean age of $26.11 \pm 4.05$ for cases and $27.57 \pm 5.27$ years for controls. Sixty $(42.3 \%)$ of cases and 57 (20.9\%) of the controls had a family size greater than five. Concerning educational status, $40(28.2 \%)$ of cases and 39 (13.7\%) of controls had no formal education and in 110 (77.5\%) of cases and 252 (88.7\%) of controls husbands had formal education (Table 1).

3.2. Obstetrics and Gynecology-Related Characteristics of Study Participants. From those who had a previous history of pregnancy, $40(28.2 \%)$ of cases and $22(7.7 \%)$ of control also had a previous history of abortion. From those who had a history of childbirth, more than half 53 (56.4\%) of cases and $43(28.3 \%)$ of controls had a birth interval of less than or equal to two years. From ANC attendees, 63 (44.4\%) of cases and $24(8.5 \%)$ of controls had vaginal bleeding (Table 2).

3.3. Disease-Related Characteristics of Study Participants. Nearly a quarter, $37(27.5 \%)$ of cases and $35(12.3 \%)$ of controls, were using different medications during current pregnancy for different reasons. More than one-third, 49 (34.5\%) of cases and 45 (15.8\%) of controls, had gastritis with peptic ulcers. Forty-six (30.3\%) of cases and 33 (11.6\%) of controls were affected by intestinal parasites (Figure 2).

\subsection{Hygiene and Sanitation-Related Characteristics of Study} Participants. More than half, 91 (64.1\%), of cases and about one-fourth, 215 (75.7\%), of controls had tape water for drinking. Around two-thirds, 93 (65.5\%), of cases and the majority, 261 (91.9\%), of controls had latrine in their compound. Nearly one-third, 67 (72\%), of cases and the majority, 235 (90\%), of controls always use the latrine (Table 3).

3.5. Determinants of Anemia in Pregnancy. Bivariate logistic regression was done for each independent variable. Multivariate analysis was done for those variables with a $p$ value $<0.25$ in the bivariate logistic regression after adjusting for covariates. Fitness of the model was also assessed. The result of multiple logistic regressions showed that pregnant mothers who had more than five family members had 2.95- 
TABLE 1: Sociodemographic characteristics of pregnant women attending antenatal follow-up-care in public hospitals of the West Shewa zone, from February to April 2019.

\begin{tabular}{|c|c|c|}
\hline Variables & Cases: $n=142(\%)$ & Controls: $n=284(\%)$ \\
\hline \multicolumn{3}{|l|}{ Age groups } \\
\hline $15-19$ & $7(4.9)$ & $12(4.2)$ \\
\hline $20-24$ & $30(21.1)$ & $91(32)$ \\
\hline $25-29$ & $68(47.9)$ & $140(49.3)$ \\
\hline $30-34$ & $18(12.7)$ & $34(12)$ \\
\hline$\geq 35$ & $19(13.4)$ & $7(2.5)$ \\
\hline \multicolumn{3}{|l|}{ Family size in number } \\
\hline$\leq 5$ & $82(57.7)$ & $227(79.1)$ \\
\hline$>5$ & $60(42.3)$ & $57(20.9)$ \\
\hline \multicolumn{3}{|c|}{ The educational level of mother } \\
\hline Have no formal education & $40(28.2)$ & $39(13.7)$ \\
\hline Have a formal education & $102(71.8)$ & $245(86.3)$ \\
\hline \multicolumn{3}{|l|}{ Marital status } \\
\hline Married & $135(95.1)$ & $272(95.8)$ \\
\hline Others $^{\mathrm{a}}$ & $7(4.9)$ & $12(4.2)$ \\
\hline \multicolumn{3}{|c|}{ The educational level of husband } \\
\hline Have no formal education & $32(22.5)$ & $32(11.3)$ \\
\hline Have a formal education & $110(77.5)$ & $252(88.7)$ \\
\hline \multicolumn{3}{|l|}{ Occupation of mother } \\
\hline Employed & $20(14.1)$ & $65(22.9)$ \\
\hline Unemployed & $122(85.9)$ & $219(77.1)$ \\
\hline \multicolumn{3}{|l|}{ Occupation of husband } \\
\hline Employed & $16(11.3)$ & $82(28.9)$ \\
\hline Unemployed & $126(88.7)$ & $202(71.1)$ \\
\hline \multicolumn{3}{|l|}{ Family income } \\
\hline$\leq 1499$ & $58(40.8)$ & $29(10.2)$ \\
\hline $1500-2499$ & $21(14.8)$ & $29(10.2)$ \\
\hline $2500-3499$ & $20(14.1)$ & $42(14.8)$ \\
\hline$\geq 3500$ & $43(30.3)$ & $184(64.8)$ \\
\hline
\end{tabular}

$a=$ single, widowed, and divorced.

fold higher odds of getting anemia than the odds of pregnant women who had $\leq 5$ family members ( $\mathrm{AOR}=2.95,95 \% \mathrm{CI}$ : 1.34-6.50). This study also showed that pregnant women who had birth intervals $\leq 2$ years had 2.61 times higher odds of getting anemia compared to those who had birth interval $>2$ years $(\mathrm{AOR}=2.61,95 \% \mathrm{CI}: 1.20-5.70)$. The result of this study signifies that the odds of getting anemia in pregnant women were higher among women who had gastritis (peptic ulcer disease) compared to their counterparts $(\mathrm{AOR}=2.85$, 95\% CI: 1.14-7.13). According to this study, pregnant mothers who had the previous history of abortion had 2.84fold higher odds of developing anemia than the odds of mothers who had no previous history of abortion $(\mathrm{AOR}=2.84,95 \%$ CI: 1.08-7.47). Pregnant women who had vaginal bleeding $(\mathrm{APH})$ during their current pregnancies had sixfold higher odds of developing anemia compared to their counterparts (AOR $=6.05,95 \%$ CI: 1.95-18.81). Similarly, the current study found that pregnant women who did not utilize latrine had 3.45-fold higher odds of getting anemia compared to the odds of those who utilize latrine $(\mathrm{AOR}=3.45,95 \%$ CI: $1.30-9.24)($ Table 4$)$.

\section{Discussion}

Anemia is one of the major public health problems globally. Its impact which includes rising the chance of maternal and child morbidity and mortality reduced cognitive and
TABLE 2: Obstetrics and gynecology-related characteristics of pregnant women attending ANC in public hospitals of the West Shewa zone, from February to April 2019.

\begin{tabular}{|c|c|c|}
\hline Variables & Cases: $n=142(\%)$ & Controls: $n=284(\%)$ \\
\hline $\begin{array}{l}\text { Regularity of menstrual cycle } \\
\text { Regular } \\
\text { Irregular }\end{array}$ & $\begin{array}{l}116(81.7) \\
26(18.3)\end{array}$ & $\begin{array}{c}256(90.1) \\
28(9.9)\end{array}$ \\
\hline $\begin{array}{l}\text { Duration of menstrual flow } \\
3-5 \text { days } \\
6-8 \text { days }\end{array}$ & $\begin{array}{l}83(58.5) \\
59(41.5)\end{array}$ & $\begin{array}{c}250(88) \\
34(12)\end{array}$ \\
\hline $\begin{array}{l}\text { Previous history of abortion } \\
\text { Yes } \\
\text { No }\end{array}$ & $\begin{array}{c}40(28.2) \\
102(78.8)\end{array}$ & $\begin{array}{r}22(7.7) \\
262(93.3) \\
\end{array}$ \\
\hline $\begin{array}{l}\text { Number of abortions } \\
\text { One } \\
2 \text { and above }\end{array}$ & $\begin{array}{l}22(55) \\
18(45) \\
\end{array}$ & $\begin{aligned} & 20(90.9) \\
& 2(9.1) \\
&\end{aligned}$ \\
\hline $\begin{array}{l}\text { Used family planning before p } \\
\text { Yes } \\
\text { No }\end{array}$ & $\begin{array}{l}\text { regnancy } \\
62(43.7) \\
80(56.3) \\
\end{array}$ & $\begin{array}{l}134(47.2) \\
150(52.8)\end{array}$ \\
\hline $\begin{array}{l}\text { Parity } \\
1-4 \\
\geq 5\end{array}$ & $\begin{array}{l}58(62.4) \\
36(37.6) \\
\end{array}$ & $\begin{array}{c}144(94.1) \\
9(5.9) \\
\end{array}$ \\
\hline $\begin{array}{l}\text { ANC follow-up for previous } p r \\
\text { Yes } \\
\text { No }\end{array}$ & $\begin{array}{r}\text { egnancy } \\
52(52.7) \\
47(47.3) \\
\end{array}$ & $\begin{array}{c}131(84.5) \\
24(15.5) \\
\end{array}$ \\
\hline $\begin{array}{l}\text { Place of delivery for the previo } \\
\text { Home } \\
\text { Health facility }\end{array}$ & $\begin{array}{l}\text { us child } \\
41(43.6) \\
53(56.4) \\
\end{array}$ & $\begin{array}{r}30(19.7) \\
122(80.3) \\
\end{array}$ \\
\hline $\begin{array}{l}\text { Mode of delivery for previous } \\
\text { Spontaneous vaginal delivery } \\
\text { Instrumental } \\
\text { Caesarean section }\end{array}$ & $\begin{array}{l}\text { child } \\
\qquad 55(90.4) \\
4(4.3) \\
5(5.3)\end{array}$ & $\begin{array}{r}124(81.6) \\
13(8.5) \\
15(9.9)\end{array}$ \\
\hline $\begin{array}{l}\text { Gravidity } \\
1-4 \\
\geq 5\end{array}$ & $\begin{array}{l}101(71.1) \\
41(28.9)\end{array}$ & $\begin{array}{c}267(94) \\
17(6) \\
\end{array}$ \\
\hline $\begin{array}{l}\text { Types of current pregnancy } \\
\text { Wanted and planned } \\
\text { Wanted but not planned } \\
\text { Neither wanted nor planned }\end{array}$ & $\begin{array}{c}87(61.3) \\
28(19.7) \\
27(19) \\
\end{array}$ & $\begin{array}{c}236(83.1) \\
30(10.6) \\
18(6.3) \\
\end{array}$ \\
\hline $\begin{array}{l}\text { The birth interval between cur } \\
<2 \text { years } \\
\geq 2 \text { years }\end{array}$ & $\begin{array}{c}\text { rent and previous bi } \\
53(56.4) \\
41(43)\end{array}$ & $\begin{array}{c}43(28.3) \\
109(71.7)\end{array}$ \\
\hline $\begin{array}{l}\text { Vaginal bleeding (antepartum } \\
\text { Yes } \\
\text { No }\end{array}$ & $\begin{array}{l}\text { hemorrhage) } \\
63(44.4) \\
79(55.6)\end{array}$ & $\begin{array}{c}24(8.5) \\
260(91.5)\end{array}$ \\
\hline
\end{tabular}

physical development in children and decreased work activity in adults is high in developing countries like Ethiopia [2]. Therefore, it is important to identify determinants that contribute to the development of anemia in pregnant women to successfully prevent it. Family size $>5$, PUD, previous history of abortion, birth interval $\leq 2$ years, APH, and unable to use latrine were determinants of anemia among pregnant women in the current study.

In this study, a family size was significantly associated with anemia. Pregnant women who had family size greater than five were at higher risk of developing anemia than those who had family size less than or equal to five. This finding is consistent with the study done in Gamo Gofa and West Arsi zones, Ethiopia, which indicated that family size greater than five was among the most significant risk factors for the development of anemia in pregnancy [31, 32]. This could be due to the sharing of resources among large families to meet 


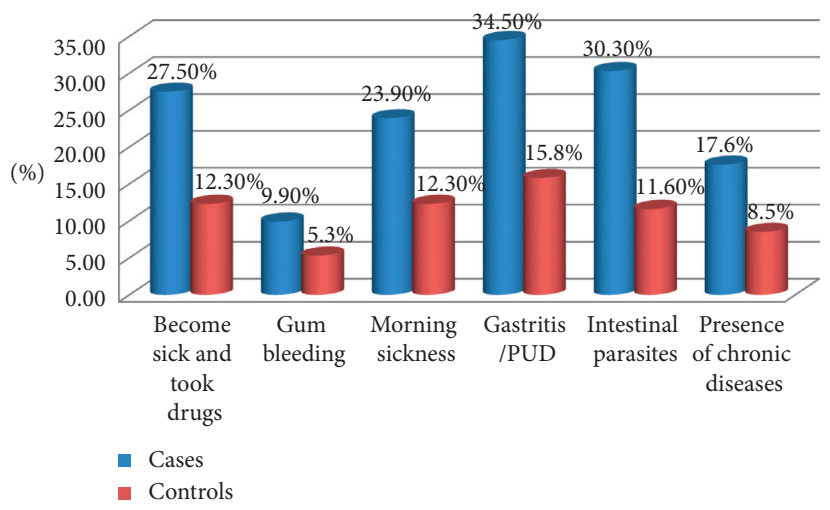

Figure 2: Percentage of disease-related characteristics of pregnant women attending ANC in public hospitals of West Shewa zone from February to April 2019.

TABLE 3: Hygiene and sanitation-related characteristics of pregnant women attending ANC care at public hospitals of West Shewa zone from February to April 2019.

\begin{tabular}{lcc}
\hline Variables & Cases: $n=142(\%)$ & Controls: $n=284(\%)$ \\
\hline Source of drinking water & & \\
Tap water & $91(64.1)$ & $215(75.7)$ \\
River water & $20(14.1)$ & $28(9.9)$ \\
Protected spring & $15(10.6)$ & $28(9.9)$ \\
Others* & $16(11.3)$ & $13(4.6)$ \\
\hline Presence of latrine & & $93(65.5)$ \\
Yes & $49(34.5)$ & $261(91.9)$ \\
No & & $23(8.11)$ \\
Continuous utilization of latrine & $67(72)$ & $235(90)$ \\
Yes & $26(28)$ & $26(10)$ \\
No & & \\
\hline Hand washing time & $134(94.4)$ & $274(96.50)$ \\
Before meal & $132(93)$ & $279(98.2)$ \\
After meal & $48(34)$ & $225(79.2)$ \\
After using the toilet & $62(43.7)$ & $215(75.7)$ \\
Before preparing food & $20(14.1)$ & $108(38)$ \\
After cleaning the bottom of children & $8(5.6)$ & $52(18.3)$ \\
After touching the bare body of another person & & \\
\hline
\end{tabular}

$*$ = protected well, unprotected well, and unprotected spring.

different basic needs and results in food insecurity which in turn leads to anemia among pregnant mothers from large families' sizes. Moreover, large family size is a proxy indicator of high parity and the short interpregnancy interval that in turn reduces maternal hemoglobin.

The birth interval was another determinant that showed a significant association with anemia in pregnant women. Birth interval $\leq 2$ years was positively associated with the occurrence of anemia in pregnancy. This finding is in agreement with a study conducted at Koppal, India, and other parts of Ethiopia [4, 31, 33-35] where birth interval less than or equal to 2 years was positively associated with the occurrence of anemia. This might be due to the depletion of iron because of frequent pregnancies and loss of blood during pregnancy, delivery, and a postpartum period where women who become pregnant in a short time before replenishing the lost blood are susceptible to anemia. Women who give birth more frequently can face stress and fear that in turn prevent them from eating adequate food which in turn leads to anemia [36].

In the current study, having previous history of abortion was statistically significantly associated with the occurrence of anemia when compared to not having previous history of abortion. This finding is consistent with other studies from Bahir Dar town and South Ethiopia where previous history of abortion was positively associated with the occurrence of anemia [37, 38]. This could be due to excess blood loss before pregnancy causes depletion of iron which in turn leads to anemia [29]. Antepartum hemorrhage during the current pregnancy was one of the independent predictors of anemia among pregnant women. Pregnant women who had antepartum hemorrhage were at higher risk of being anemic than those who did not have antepartum hemorrhage during pregnancy. This finding is consistent with the study done in Bahir Dar town [38]. This might be due to the fact that antepartum hemorrhage 
TABLE 4: Determinants of anemia among pregnant women attending antenatal care follow-up in public hospitals of the West Shewa zone, from February to April 2019 (multivariable analysis).

\begin{tabular}{|c|c|c|c|c|}
\hline Variables & Cases: $n=142(\%)$ & Controls: $n=284(\%)$ & COR $(95 \% \mathrm{CI})$ & AOR $(95 \% \mathrm{CI})$ \\
\hline \multicolumn{5}{|c|}{ Family size } \\
\hline$\leq 5$ & $82(57.7)$ & $227(79.1)$ & 1 & 1 \\
\hline$>5$ & $60(42.3)$ & $57(20.9)$ & $3.1(1.99,4.80)$ & $3.81(1.73,8.39)^{* *}$ \\
\hline \multicolumn{5}{|c|}{ Previous history of abortion } \\
\hline Yes & $40(28.2)$ & $22(7.7)$ & $4.67(2.65,8.24)$ & $2.84(1.08-7.47)^{* *}$ \\
\hline No & $102(78.8)$ & $262(93.3)$ & 1 & 1 \\
\hline \multicolumn{5}{|c|}{ Birth interval } \\
\hline$\leq 2$ years & $53(56.4)$ & $43(28.3)$ & $3.28(1.91,5.62)$ & $2.26(1.16-4.40)^{* *}$ \\
\hline$>2$ years & $41(43)$ & $109(71.7)$ & 1 & 1 \\
\hline \multicolumn{5}{|c|}{ Vaginal bleeding during current pregnancy } \\
\hline Yes & $63(44.4)$ & $24(8.5)$ & 1 & 1 \\
\hline No & $79(55.6)$ & $260(91.5)$ & $2.66(1.48,4.79)$ & $6.05(1.95,18.81)^{* *}$ \\
\hline \multicolumn{5}{|c|}{ Presence of gastritis or PUD } \\
\hline Yes & $49(34.5)$ & $45(15.8)$ & $2.80(1.75,4.4)$ & $2.85(1.14,7.13)^{* *}$ \\
\hline No & $93(65.5)$ & $239(84.2)$ & 1 & 1 \\
\hline \multicolumn{5}{|c|}{ Continuous utilization of latrine } \\
\hline Yes & $67(72)$ & $235(90)$ & 1 & 1 \\
\hline No & $26(28)$ & $26(10)$ & $3.51(1.91,6.44)$ & $3.45(1.30-9.24)^{* *}$ \\
\hline
\end{tabular}

causes depletion of iron which in turn causes anemia among pregnant women $[39,40]$.

The presence of gastritis or PUD was statistically significantly associated with the occurrence of anemia among pregnant women during pregnancy. This finding is comparable with the study conducted in Hawassa and Yirgalem cities in which women who had gastritis were four times more likely to develop anemia than their counterparts [11]. This might be due to the fact that peptic ulcer disease causes upper gastrointestinal bleeding (blood loss) and loss of appetite that causes anemia [41].

Unable to use latrine continuously was also found to play a major driving role in the incident of anemia among pregnant women. Unable to use latrine continuously during pregnancy was positively associated with the occurrence of anemia. This could be because if one does not use toilet, open-field defecation is common practice that leads to contamination of environment and water which causes the intestinal parasites which in turn causes anemia [42]. This is because intestinal parasite consumes a digested diet from the intestine which in turn leads to micronutrient deficiency, specifically iron, that causes anemia. Parasite diseases, especially hookworms, contribute to iron deficiency anemia [43]. As far as we know, our study is the first or unique to identify such a significant association between not using toilets and anemia among pregnant women in Ethiopia.

\section{Limitation of the study}

The study may be affected by recall bias because it was retrospective and may be susceptible to social desirability bias.

\section{Conclusion}

In this study, family size greater than five, birth interval less than or equal to two years, gastritis or peptic ulcer diseases, having the previous history of abortion, vaginal bleeding during pregnancy, and not using toilet were identified determinants of anemia among pregnant women. Therefore, intervention on anemia prevention should consider the promotion of family planning methods, counseling and awareness creation on the importance of latrine construction and continuous utilization, and early identification and treatment of PUD among pregnant mothers through media, at ANC follow-up and through community engagements. Finally, we recommend further community-based study with large sample size and more strong study design to determine other determinants of anemia among pregnant women to address those pregnant women unable to attend antenatal care at public hospitals.

\section{Abbreviations \\ ANC: Antenatal care \\ APH: Antepartum hemorrhage \\ HIV: Human Immunodeficiency Virus \\ PUD: Peptic ulcer disease \\ WHO: World Health Organization.}

\section{Data Availability}

The data used to support the findings of this study cannot be made publically available at present time. It will be made available from the corresponding author upon a reasonable request. 


\section{Conflicts of Interest}

The authors declare that they have no conflicts of interest regarding publication of this paper.

\section{Authors' Contributions}

$\mathrm{BSD}, \mathrm{ETB}$, and $\mathrm{GAB}$ involved in idea creation, proposal development, supervising data collection, data analysis, and interpreting results. TAG, AAG, HOD, MBS, AFA, and LZS were involved in editing, supervision, and guiding during the whole research proposal development and research result writing, while $\mathrm{BSD}$ and $\mathrm{GAB}$ contributed to the manuscript preparation. All the authors read and approved the manuscript.

\section{Acknowledgments}

We would like to express our great thanks to the Ambo University Department of Public Health for facilitating this thesis work. Our deepest thanks shall go to all study participants, data collectors, and supervisors for their patience and cooperation up to the end of the data collection period.

\section{References}

[1] B. D. Benoist, E. McLean, I. Egll, and M. Cogswell, Worldwide Prevalence of Anaemia 1993-2005: WHO Global Database on Anaemia, WHO, Geneva, Switzerland, 2008.

[2] G. A. Stevens, M. M. Finucane, L. M. De-Regil et al., "Global, regional, and national trends in haemoglobin concentration and prevalence of total and severe anaemia in children and pregnant and non-pregnant women for 1995-2011: a systematic analysis of population-representative data," The Lancet Global Health, vol. 1, no. 1, pp. e16-e25, 2013.

[3] World Health Organization, The Global Prevalence of Anaemia in 2011, World Health Organization, Geneva, Switzerland, 2015.

[4] G. M. Kassa, A. A. Muche, A. K. Berhe, and G. A. Fekadu, "Prevalence and determinants of anemia among pregnant women in Ethiopia; a systematic review and meta-analysis," BMC Hematology, vol. 17, no. 1, p. 17, 2017.

[5] Y. Balarajan, U. Ramakrishnan, E. Özaltin, A. H. Shankar, and S. V. Subramanian, "Anaemia in low-income and middleincome countries," The Lancet, vol. 378, no. 9809, pp. 2123-2135, 2011.

[6] N. J. Kassebaum, R. Jasrasaria, M. Naghavi et al., "A systematic analysis of global anemia burden from 1990 to 2010," Blood, vol. 123, no. 5, pp. 615-624, 2014.

[7] F. Bánhidy, N. Ács, E. H. Puhó, and A. E. Czeizel, "Iron deficiency anemia: pregnancy outcomes with or without iron supplementation," Nutrition, vol. 27, no. 1, pp. 65-72, 2011.

[8] F. Kefiyalew, E. Zemene, Y. Asres, and L. Gedefaw, "Anemia among pregnant women in Southeast Ethiopia: prevalence, severity and associated risk factors," BMC Research Notes, vol. 7, no. 1, p. 771, 2014.

[9] World Health Organization, Global Nutrition Targets 2025: Wasting Policy Brief, Geneva, Switzerland, 2014.

[10] A. Abriha, M. Yesuf, and M. Wassie, "Prevalence and associated factors of anemia among pregnant women of Mekelle town: a cross sectional study," BMC Research Notes, vol. 7, no. 1, p. 888, 2014.
[11] B. Argaw, A. Argaw-Denboba, B. Taye, A. Worku, and A. Worku, "Major risk factors predicting anemia development during pregnancy: unmatched-case control study," Jcournal of Community Medicine \& Health Education, vol. 5, no. 353, pp. 2161-0711, Article ID 1000353, 2015.

[12] G. C. Di Renzo, J. A. Conry, J. Blake et al., "International federation of gynecology and obstetrics opinion on reproductive health impacts of exposure to toxic environmental chemicals," International Journal of Gynecology \& Obstetrics, vol. 131, no. 3, pp. 219-225, 2015.

[13] J. T. Griffin, T. D. Hollingsworth, L. C. Okell et al., "Reducing plasmodium falciparum malaria transmission in Africa: a model-based evaluation of intervention strategies," PLoS Medicine, vol. 7, no. 8, Article ID e1000324, 2010.

[14] World Health Organization, Global Nutrition Targets 2025: Policy Brief Series, World Health Organization, Geneva, Switzerland, 2014.

[15] J. Jennings and M. Hirbaye, Review of Incorporation of Essential Nutrition Actions into Public Health Programs in Ethiopia, The Food and Nutrition Technical Assistance Project (FANTA), Washington, DC, USA, 2008.

[16] A. Gebreweld and A. Tsegaye, "Prevalence and factors associated with anemia among pregnant women attending antenatal clinic at st. Paul's hospital millennium medical college, addis ababa, Ethiopia," Advances in Hematology, vol. 2018, Article ID 3942301, 8 pages, 2018.

[17] F. Asrie, "Prevalence of anemia and its associated factors among pregnant women receiving antenatal care at Aymiba Health Center, northwest Ethiopia," Journal of Blood Medicine, vol. 8, pp. 35-40, 2017.

[18] B. Ayano and B. Amentie, "Assessment of prevalence and risk factors for anemia among pregnant mothers attending anc clinic at adama hospital medical collage, adama, Ethiopia, 2017," Journal of Gynecology and Obstetrics, vol. 6, no. 3, pp. 31-39, 2018.

[19] M. Alem, B. Enawgaw, A. Gelaw, T. Kenaw, M. Seid, and Y. Olkeba, "Prevalence of anemia and associated risk factors among pregnant women attending antenatal care in azezo health center gondar town, Northwest Ethiopia," Journal of Interdisciplinary Histopathology, vol. 1, no. 3, pp. 137-144, 2013.

[20] J. A. Haidar and R. S. Pobocik, "Iron deficiency anemia is not a rare problem among women of reproductive ages in Ethiopia: a community based cross sectional study," BMC Hematology, vol. 9, no. 1, p. 7, 2009.

[21] L. Gedefaw, A. Ayele, Y. Asres, and A. Mossie, "Anaemia and associated factors among pregnant women attending antenatal care clinic in Walayita Sodo town, Southern Ethiopia," Ethiopian Journal of Health Sciences, vol. 25, no. 2, pp. 155164, 2015.

[22] M. Melku, Z. Addis, M. Alem, and B. Enawgaw, "Prevalence and predictors of maternal anemia during pregnancy in Gondar, Northwest Ethiopia: an institutional based crosssectional study," Anemia, vol. 2014, Article ID 108593, 9 pages, 2014.

[23] D. Shitie, T. Zewde, and Y. Molla, "Anemia and other hematological profiles of pregnant women attending antenatal care in Debre Berhan Referral Hospital, North Shoa, Ethiopia," BMC Research Notes, vol. 11, no. 1, p. 704, 2018.

[24] D. Lelissa, M. Yilma, W. Shewalem et al., "Prevalence of anemia among women receiving antenatal care at boditii health center, southern Ethiopia," Age, vol. 15, no. 19, p. 25, 2015. 
[25] A. Gebre and A. Mulugeta, "Prevalence of Anemia and associated factors among pregnant women in north western zone of Tigray, northern Ethiopia: a cross-sectional study," Journal of Nutrition and Metabolism, vol. 2015, Article ID 165430, 7 pages, 2015.

[26] F. A. Mekonnen, Y. A. Ambaw, and G. T. Neri, "Socioeconomic determinants of anemia in pregnancy in north shoa zone, Ethiopia," PloS One, vol. 13, no. 8, Article ID e0202734, 2018.

[27] WS Office, Health Managment Information System Third Quarter Report, Vol. 24, National Health Mission, Ambo, Ethiopia, 2019.

[28] E. N. Nwodo, S. E. Yakubu, E. D. Jatau, and A. Yabaya, "Seroprevalence of Helicobacter pylori infection in patients with gastritis and peptic ulcer disease in Kaduna, Kaduna State, Nigeria," African Journal of Basic \& Applied Sciences, vol. 1, no. 5-6, pp. 123-128, 2009.

[29] S. E. Tadesse, O. Seid, A. Fekadu, Y. G. Mariam, K. Endris, and A. Bitew, "Determinants of anemia among pregnant mothers attending antenatal care in Dessie town health facilities, northern central Ethiopia, unmatched case-control study," PloS One, vol. 12, no. 3, Article ID e0173173, 2017.

[30] S. Sperandei, "Understanding logistic regression analysis," Biochemia Medica, vol. 24, no. 1, pp. 12-18, 2014.

[31] A. Bekele, M. Tilahun, and A. Mekuria, "Prevalence of anemia and its associated factors among pregnant women attending antenatal care in health institutions of Arba Minch Town, Gamo Gofa Zone, Ethiopia: a cross-sectional study," Anemia, vol. 2016, Article ID 1073192, 9 pages, 2016.

[32] N. Obse, A. Mossie, and T. Gobena, "Magnitude of anemia and associated risk factors among pregnant women attending antenatal care in Shalla Woreda, West Arsi Zone, Oromia Region, Ethiopia," Ethiopian Journal of Health Sciences, vol. 23, no. 2, pp. 165-173, 2013.

[33] B. N. Seema, "Prevalence of anemia among pregnant women in rural Koppal: a study from teaching hospital, Koppal, India," International Journal of Reproduction, Contraception, Obstetrics and Gynecology, vol. 6, no. 9, pp. 3792-3795, 2017.

[34] A. Abay, H. W. Yalew, A. Tariku, and E. Gebeye, "Determinants of prenatal anemia in Ethiopia," Archives of Public Health, vol. 75, no. 1, p. 51, 2017.

[35] W. Getahun, T. Belachew, and A. D. Wolide, "Burden and associated factors of anemia among pregnant women attending antenatal care in southern Ethiopia: cross sectional study," BMC Research Notes, vol. 10, no. 1, p. 276, 2017.

[36] T. Gelaw, T. G. Ketema, K. Beyene, M. K. Gurara, and G. G. Ukke, "Fear of childbirth among pregnant women attending antenatal care in Arba Minch town, southern Ethiopia: a cross-sectional study," BMC Pregnancy and Childbirth, vol. 20, no. 1, pp. 1-7, 2020.

[37] B. Zekarias, A. Meleko, A. Hayder, A. Nigatu, and T. Yetagessu, "Prevalence of anemia and its associated factors among pregnant women attending antenatal care (ANC) in Mizan Tepi University Teaching Hospital, South West Ethiopia," Health Science Journal, vol. 11, no. 5, pp. 1-8, 2017.

[38] D. Getaneh, A. Bayeh, B. Belay, T. Tsehaye, and Z. Mekonnen, "Assessment of the prevalence of anemia and its associated factors among pregnant women in bahir dar city administration, north-west Ethiopia," Journal of Pregnancy and Child Health, vol. 5, no. 367, p. 2, 2018.

[39] P. Kumar, P. Pore, and U. Patil, "Maternal anaemia and its impact on perinatal outcome in a tertiary care hospital of Pune," Maharashtra I JBAMR, vol. 1, pp. 111-119, 2012.
[40] E. K. Shipala, G. A. Sowayi, M. P. Kagwiria, and E. O. Were, "Prevalence of anemia among teenage pregnant girls attending antenatal clinic in two health facilities in bungoma district, western Kenya," Journal of Biology, Agriculture and Healthcare, vol. 3, no. 6, 2013.

[41] P. Malfertheiner, F. K. L. Chan, and K. E. L. McColl, "Peptic ulcer disease," The Lancet, vol. 374, no. 9699, pp. 1449-1461, 2009.

[42] D. Mara, J. Lane, B. Scott, and D. Trouba, "Sanitation and health," PLoS Medicine, vol. 7, no. 11, 2010.

[43] T. W. Gyorkos and N. L. Gilbert, "Blood drain: soil-transmitted helminths and anemia in pregnant women," PLoS Neglected Tropical Diseases, vol. 8, no. 7, Article ID e2912, 2014. 